\title{
Original Communication
}

\section{Bioavailability and Chemical/ Functional Aspects of Synthetic MK-7 vs Fermentation-Derived MK-7 in Randomised Controlled Trials} Mona Møller ${ }^{1}$, Ingrid M. Fange Gjelstad ${ }^{2}$, Ingebjørg Baksaas ${ }^{3}$,
Tone Grande $^{3}$, Inger Reidun Aukrust ${ }^{4}$, and Christian A. Drevon ${ }^{2}$

\author{
'Kappa Bioscience AS, Oslo, Norway \\ ${ }^{2}$ Department of Nutrition, Institute of Basic Medical Sciences, \\ Faculty of Medicine, University of Oslo, Oslo, Norway \\ ${ }^{3}$ Mericon AS, Skien, Norway \\ ${ }^{4}$ Synthetica AS, Oslo, Norway
}

Received: May 27, 2015; Accepted: September 29, 2015

\begin{abstract}
We investigated the bioavailability of a synthetic form of the vitamin $\mathrm{K}_{2}$ molecule menaquinone-7 (MK-7) in a randomised single-blinded two-way cross-over study. Healthy subjects (20-66 years of age) took a single $180 \mu \mathrm{g}$ dose of synthetic MK-7 or fermentation-derived MK-7, and serum MK-7 concentrations were monitored for 72 hours to calculate $\mathrm{AUC}(0-72 \mathrm{~h})$ and $\mathrm{C}_{\max }$. We also compared the biological effects of placebo, fermentation-derived MK-7 $(90 \mu \mathrm{g})$ and 3 doses of synthetic MK-7 $(45,90$ and $180 \mu \mathrm{g})$ in a randomised double-blinded parallel study. Healthy subjects (20-60 years of age) took one of the supplements daily for 43 days, and the fraction of carboxylated osteocalcin (OC) was compared between day 1 and day 43 as a marker for vitamin K activity. In the bioavailability study, the $90 \%$ confidence interval for the ratio of the AUC $(0-72 \mathrm{~h})$ values for synthetic and fermentationderived MK-7 was $83-111$, indicating bioequivalence. The $90 \%$ confidence interval for the Cmax ratio was $83-131$. The serum concentrations of carboxylated $\mathrm{OC}$ and undercarboxylated $\mathrm{OC}$ were increased $(p=0.01)$ and reduced $(p=0.02)$, respectively, after daily intake of $180 \mu \mathrm{g}$ of synthetic MK-7 for 43 days, indicating increased vitamin $\mathrm{K}$ activity. Across both studies, only 1 participant reported an adverse event (dry mouth; $180 \mu \mathrm{g}$ synthetic MK-7 group, functional study) that was considered possibly related to synthetic MK-7 supplementation. Our findings provide evidence that the tested synthetic form of MK-7 is bioequivalent to fermentation-derived MK-7, exhibits vitamin K activity and is well tolerated in healthy subjects.
\end{abstract}

Key words: Menaquinone-7, MK-7, vitamin $\mathrm{K}_{2}, \mathrm{~K} 2 \mathrm{VITAL}^{\circledR}$, biological availability, bioequivalence, equivalency, osteocalcin 


\section{Introduction}

Vitamin K includes a group of structurally related compounds named phylloquinone (vitamin $\mathrm{K}_{1}$ ) and menaquinones (vitamin $\mathrm{K}_{2}$ ) [1]. Vitamin $\mathrm{K}_{1}$ is quantitatively the major dietary source of vitamin $\mathrm{K}$ and is found in green vegetables such as broccoli, cabbage, and spinach [2]. Menaquinones are vitamin $\mathbf{K}_{2}$ molecules that can be distinguished from each other by the number of isoprene units in their side chain (up to 13). Their names are abbreviated as MK-n, where $\mathrm{n}$ represents the number of isoprene units. The long-chain menaquinones MK-7, MK-8, MK-9, and MK-10 are found in low quantities in fermented products such as cheese, as well as egg yolk, meat, and curd [3, 4]. The richest natural source of vitamin $\mathrm{K}_{2}$ is the traditional Japanese food natto, which is made from bacterially fermented soybeans and contains high concentrations of MK-7 [1].
Vitamin $\mathrm{K}_{2}$ is a co-factor for carboxylation of glutamate residues in proteins called Gla proteins. Two well-characterised Gla proteins are osteocalcin (OC) and matrix Gla protein (MGP), both of which have been implicated in bone mineralisation. Vitamin $\mathrm{K}$ is essential for carboxylation of these proteins and their ability to bind calcium [3]. OC is produced by osteoblasts during bone formation and must be carboxylated in order to accumulate in bone matrix. Although it has been suggested that $\mathrm{OC}$ is important for bone mineralisation [5], its precise role is unclear because OC-knockout mice have similar levels of bone mineralisation as control mice [6]. Evidence that MGP promotes bone mineralisation comes from the observation that mice lacking MGP develop osteopenia and suffer from fractures [7].

The extent of OC carboxylation may be the most sensitive marker of human vitamin $\mathrm{K}$ status $[8,9]$.

A

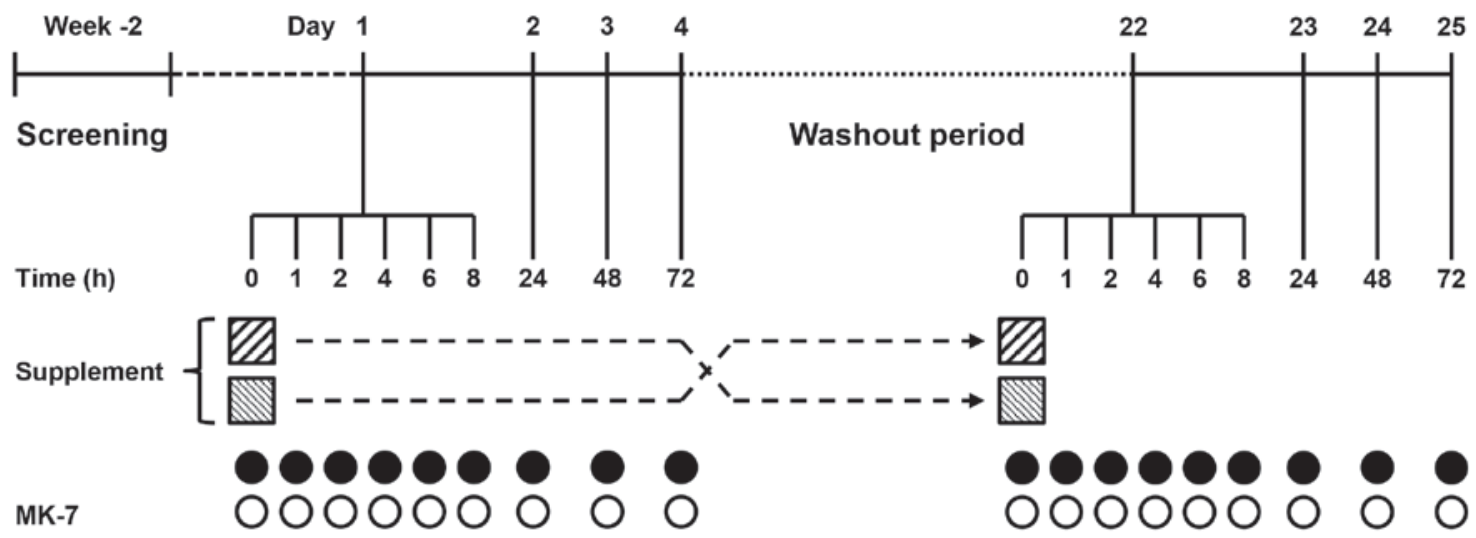

B

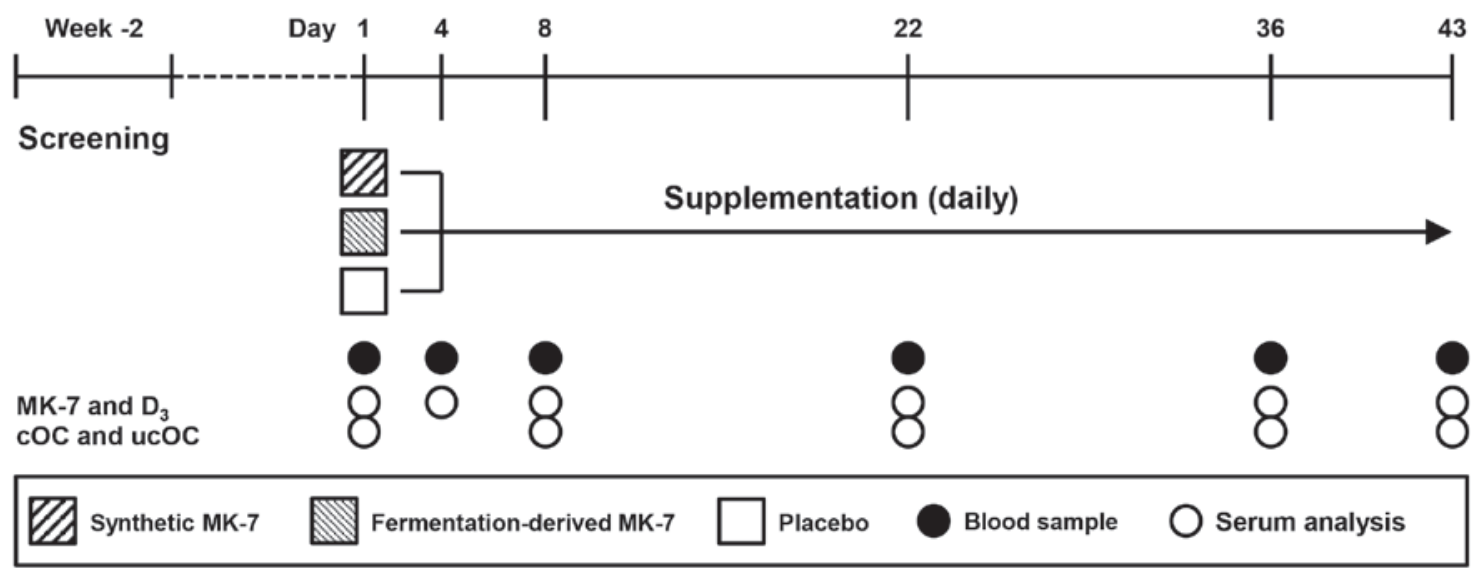

Figure 1: Study design A) Bioavailability B) Functional aspects as monitored by carboxylation of osteocalcin. Abbreviations: D3, 25-hydroxyvitamin D3; cOC, carboxylated osteocalcin; ucOC, undercarboxylated osteocalcin. 
In healthy adults, about $30 \%$ of circulating OC is undercarboxylated $[10,11]$. Increased vitamin $\mathrm{K}$ intake causes a rapid decline in undercarboxylated OC (ucOC) $[8,12]$, suggesting possible subclinical vitamin $\mathrm{K}$ deficiency in "healthy" bone tissue [4]. A high serum concentration of ucOC is correlated with an increased risk of hip fractures $[13,14]$.

The importance of vitamin $\mathrm{K}_{2}$ for bone health was recently documented in a 3-year placebo-controlled study among 244 healthy postmenopausal women. Daily intake of $180 \mu \mathrm{g}$ of MK-7 significantly reduced the age-related decline in bone mineral content and bone mineral density (BMD) in the lumbar spine and femoral neck [15]. Furthermore, MK-7 preserved bone strength as compared to placebo treatment. The roles of vitamin $\mathrm{K}$ (including menaquinones) in bone health have been reviewed [16-18], and a synthetic form of the short-chain menaquinone MK-4 has been approved by the Japanese Ministry of Health as a treatment for osteoporosis [19].

Because of beneficial effects in some clinical trials, MK-7 has received great attention as a food supplement. Studies have shown that dietary intake of MK-7 is low in Europe and the USA [1, 2]. By contrast, in Japan the intake of natto in some regions provides a high intake of MK-7 [20]. A population-based study in Japan showed a positive association between natto intake and BMD in the femoral neck in post-menopausal women [21], and it has been postulated that supplementation of the Western diet with MK-7 might prevent osteoporosis [22].

A major difference between vitamin $\mathrm{K}_{1}$ and MK-7 is in their half-lives. Fat-soluble vitamins such as vitamin $\mathrm{K}$ are absorbed well in the presence of fat. However, vitamin $\mathrm{K}_{1}$ quickly disappears from the circulation (half-life $\sim 1-2 \mathrm{~h}$ ). MK-7, by contrast, has a half-life of days [9]. This difference may be due to differences in molecular structure, causing differences in uptake, transport in blood, distribution, and metabolism. There is also a large difference in steady-state concentration: the serum concentration of MK-7 is substantially higher than that of vitamin $\mathrm{K}_{1}$ when subjects are given equimolar amounts. The longer half-life of MK-7 means that it remains longer in the blood and is far more accessible to extra-hepatic tissues such as bone and blood vessel walls, probably promoting more efficacious carboxylation of OC and MGP [9].

Vitamin $\mathrm{K}_{2}$ is documented to be safe, with no side effects reported in humans $[15,23]$ or when tested at very high doses in rats [24].

We have developed a new source of this important vitamin: a synthetic all-trans form of MK-7 approved as a dietary supplement by the European Food Safety
Authority (EFSA). The synthesis of MK-7 involves many steps and it is important to produce the all-trans form because the cis isomers have little or no biological activity $[25,26]$.

Most vitamins are made synthetically. Thus, it is of interest to evaluate whether synthetic MK-7 is chemically identical to and has similar biological effects as fermentation-derived MK-7. The objectives of this study were to investigate the pharmacokinetics and biological function of synthetic MK-7 in healthy volunteers. To determine whether synthetic MK-7 and fermentation-derived MK-7 are bioequivalent when administered as a single $180-\mu \mathrm{g}$ dose, we performed a cross-over trial. In a second trial, we investigated the dose effects of synthetic MK-7 on serum levels of MK-7, 25-hydroxyvitamin $\mathrm{D}_{3}$, carboxylated OC (cOC) and ucOC.

\section{Subjects and methods}

\section{Design}

This research project includes a bioavailability study and a functional study. Both studies were conducted at Oslo Innovation Center between March 3 and May 6, 2010, by the company DBG AS (Oslo). The bioavailability study was conducted as a randomised single-blinded two-way cross-over study with two 72-h observation periods and a 17-day washout period (Figure 1A). The functional study was conducted as a randomised double-blinded parallel 5-arm study with a 43-day supplementation period (Figure 1B).

\section{Ethics}

The studies, including the case report forms (CRFs), subject information and informed consent forms, were approved by the Regional Committee for Medical and Health Research Ethics (REC South East, University of Oslo; reference no. 2009/2191).

The studies were conducted in compliance with Good Clinical Practice (GCP) as described in ICH (International Conference on Harmonization) E6. The studies followed the guidelines of the Declaration of Helsinki.

All participants were given written and oral information about the study, and signed a consent form before inclusion in the study. Separate forms were used for the bioavailability study and the functional study. 


\section{Subjects}

Participants were recruited through information (including posters) at the University of Oslo and the Oslo Innovation Center. Subjects were screened during week -2 relative to the start of supplementation. Men and women meeting all the following inclusion criteria were eligible to participate in the bioavailability or functional study:

- Age 18-65 years

- BMI: $18.5-27 \mathrm{~kg} / \mathrm{m}^{2}$

- Signed informed consent

Subjects meeting any of the following exclusion criteria were ineligible to participate in the bioavailability or functional study:

- Chronic disease (except allergy)

- Use of vitamin K supplements within the last month

- Current treatment with vitamin K antagonists (e.g. warfarin)

- Current daily chronic drug treatment (except contraceptives)

- Current pregnancy, confirmed by measurement of serum human chorionic gonadotropin by Advia Centaur XP immunoassay (Siemens AS, Oslo, Norway) by Fürst AS (Oslo, Norway)

- Current lactation

- C-reactive protein $(\mathrm{CRP})>10 \mathrm{mg} / \mathrm{L}$, serum creatinine $>90 \mu \mathrm{mol} / \mathrm{L}$ (women) or $>105 \mu \mathrm{mol} / \mathrm{L}$ (men), alanine aminotransferase (ALAT) $>45 \mathrm{U} / \mathrm{L}$ (women) or $>70$ $\mathrm{U} / \mathrm{L}$ (men) or serum total cholesterol $>7 \mathrm{mmol} / \mathrm{L}$

- Drug abuse

- Current participation in another clinical study

- Inability to comply with the protocol, in the opinion of the investigator

Based on the sample size of a previous bioavailability study of MK-7 [9], we aimed to include 16 subjects in the bioavailability study. 19 subjects satisfied the eligibility criteria and agreed to participate in the bioavailability study. 48 subjects satisfied the eligibility criteria and agreed to participate in the functional study.

\section{Supplementation}

The active ingredient in the investigational product, K2VITAL ${ }^{\circledR}$ MK-7 (synthetic MK-7), was manufactured by Synthetica AS (Oslo, Norway) in accordance with good manufacturing practice (GMP). Soft-shell capsules of K2VITAL ${ }^{\circledR}$ MK-7 formulated in sunflower oil were produced by Curtis Healthcare (Poznan, Poland). Each capsule was designed to contain $45 \mu \mathrm{g}$ of synthetic MK-7. The active ingredient in the control product was fermentation-derived MK-7 produced by J-Oil Mills (Japan). The control product consisted of soft-shell capsules of fermentation-derived MK-7 in sunflower oil and was produced by Curtis Healthcare. Each capsule was designed to contain $45 \mu \mathrm{g}$ of fermentation-derived MK-7. The placebo consisted of soft-shell capsules containing the same sunflower oil as the capsules with synthetic MK-7 and fermentationderived MK-7. The capsules were packaged by the company Farmaka AS (Askim, Norway).

For both studies, participants were numbered and treated according to a computer-generated random allocation sequence.

\section{Bioavailability study}

Subjects were randomised 1:1 to supplementation with synthetic MK-7 first or with fermentation-derived MK-7 first by simple randomisation. 4 capsules (180 $\mu \mathrm{g}$ ) of synthetic MK-7 or fermentation-derived MK-7 were administered orally as a single dose on day 1 and day 22. The capsules were labelled as "A" or "B", and participants were blinded to their supplement allocation. The supplements were administered in conjunction with a standard breakfast containing $\sim 25 \mathrm{~g}$ of fat.

\section{Functional study}

Subjects were randomised 1:2:2:2:2 to placebo, $45 \mu \mathrm{g}$ synthetic MK-7, $90 \mu \mathrm{g}$ synthetic MK-7, $180 \mu \mathrm{g}$ synthetic MK-7 or $90 \mu \mathrm{g}$ fermentation-derived MK-7, respectively, by simple randomisation.

The supplements were administered orally once daily for 6 weeks as follows:

- Placebo: 4 placebo capsules

. $45 \mu \mathrm{g}$ synthetic MK-7: 1 K2VITAL ${ }^{\circledR}$ capsule +3 placebo capsules

. $90 \mu \mathrm{g}$ synthetic MK-7: 2 K2VITAL $^{\circledR}$ capsules + 2 placebo capsules

- $180 \mu \mathrm{g}$ synthetic MK-7: 4 K2VITAL ${ }^{\circledR}$ capsules

- Fermentation-derived MK-7 $(90 \mu \mathrm{g})$ : 2 fermentationderived MK-7 capsules +2 placebo capsules.

The capsules were packaged into daily bags ( 4 capsules per bag) labelled with subject identification numbers. The participants, principal investigator and researchers who analysed the study outcomes were all blinded to the supplement allocations. The participants were asked to take the capsules once in the morning in conjunction with a breakfast containing some fat. On days when blood samples were taken, the capsules were taken after blood sampling. At the end of the study, 
any unused bags were returned to the investigator. The participants recorded their capsule consumption in a diary, and the diaries were checked during each study visit to assess compliance.

\section{Outcome measures}

\section{Bioavailability study}

Blood samples $(3 \mathrm{~mL})$ were obtained at the following time points (relative to MK-7 administration) for measurement of serum MK-7 levels during observation period 1 (days 1-4): 0, 1, 2, 4, 6, 8, 24, 48, and $72 \mathrm{~h}$ (figure 1A). After a 17-day washout period, blood samples were obtained at the same time points relative to MK-7 administration for measurement of serum MK-7 levels during observation period 2 (days 22-25). The 0-h samples were obtained immediately before the start of capsule supplementation. Serum was isolated from blood by standard methods and stored at $-20^{\circ} \mathrm{C}$ before analysis. Serum concentrations of MK-7 were measured by the contract laboratory Vitas AS (Oslo) by a validated method (internal report, Vitas AS). Briefly, serum samples were thawed and mixed. Then, serum samples, calibration standards, and quality control samples $(80 \mu \mathrm{L})$ were combined with $300 \mu \mathrm{L}$ of isopropanol containing ${ }^{18} \mathrm{O}$ MK-7 $(10 \mathrm{ng} / \mathrm{mL})$ as an internal standard. The samples were shaken at 1350 $\mathrm{rpm}$ for $6 \mathrm{~min}$ to precipitate proteins. The isopropanol layer containing MK-7 was separated from the precipitated proteins and analysed by liquid chromatographytandem mass spectrometry (LC-MS/MS). Chromolith $^{\circledR}$ SpeedROD RP-18e $(4.6 \mathrm{~mm} \times 50 \mathrm{~mm}$, Merck $)$ was used as the analytical column and Chromolith RP-18e (4.6 mm $\times 10 \mathrm{~mm}$, Merck) as the guard column. The injection volume was $50 \mu \mathrm{L}$. MK-7 concentrations were used to calculate area under the serum concentration versus time curve $(\mathrm{AUC})_{(0-48 \mathrm{~h})}, \mathrm{AUC}_{(0-72 \mathrm{~h})}$, $\mathrm{C}_{\max }, \mathrm{T}_{\max }$ and $\mathrm{t}_{1 / 2}$ as the outcome measures.

\section{Functional study}

Blood samples $(2 \times 3 \mathrm{~mL})$ were collected before MK-7/ placebo administration on days $1,4,8,22,36$, and 43(+2) for measurement of MK-7 and 25-hydroxyvitamin $\mathrm{D}_{3}$ levels (figure $1 \mathrm{~B}$ ). Blood samples obtained on days $1,8,22,36$ and $43(+2)$ were also used for measurement of serum concentrations of $\mathrm{cOC}$ and ucOC. Serum was isolated from blood by standard methods and stored at $-20^{\circ} \mathrm{C}$ before analysis.
Serum MK-7 levels were measured by Vitas AS as described above. Serum 25-hydroxyvitamin $\mathrm{D}_{3}$ was measured by Fürst AS by LC-MS/MS. Briefly, serum samples were subjected to protein precipitation with methanol containing the internal standard deuterated 25 -hydroxyvitamin $\mathrm{D}_{3}$, followed by liquid-liquid extraction with heptane and analysis by LC-MS/MS with multiple reaction monitoring.

Serum cOC and ucOC were measured by Vitas AS using two enzyme immunoassay kits (cat. nos. MK111 and MK118, respectively) from Takara Bio (Ōtsu, Japan) according to the manufacturer's protocols.

\section{Safety assessments}

Information on adverse events was obtained throughout both studies by recording all kinds of discomfort

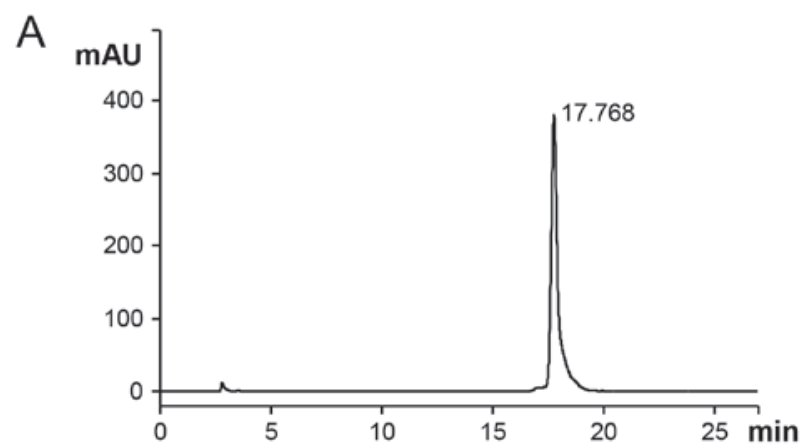

B

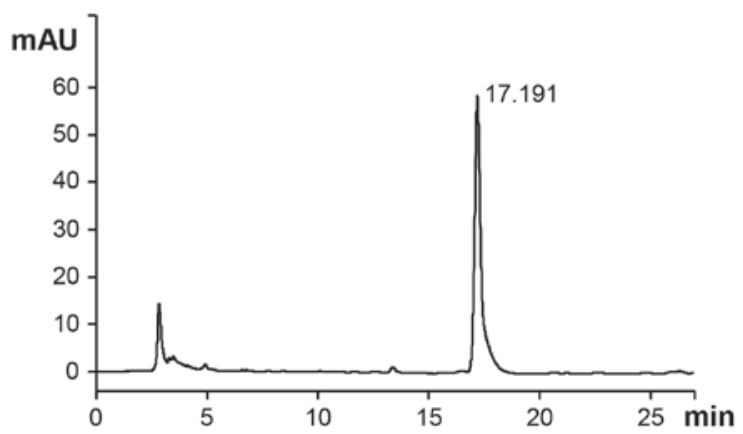

C

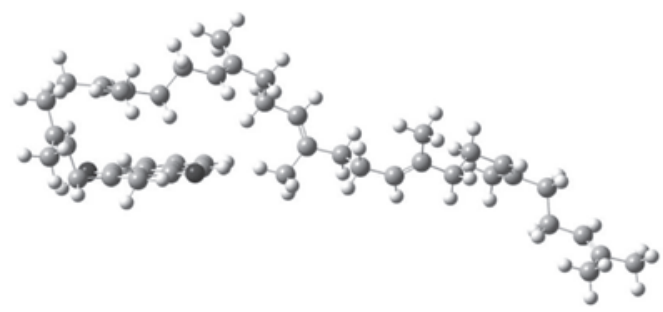

Figure 2: Purity and molecular structure of MK-7. A) and B) Chromatograms from HPLC analysis (C30 reversedphase column, detection at $270 \mathrm{~nm}$ ). A) Synthetic MK-7. B) Fermentation-derived MK-7. C) 3D model of all-trans MK-7. Atoms: black $=$ oxygen, grey $=$ carbon, white $=$ hydrogen . 


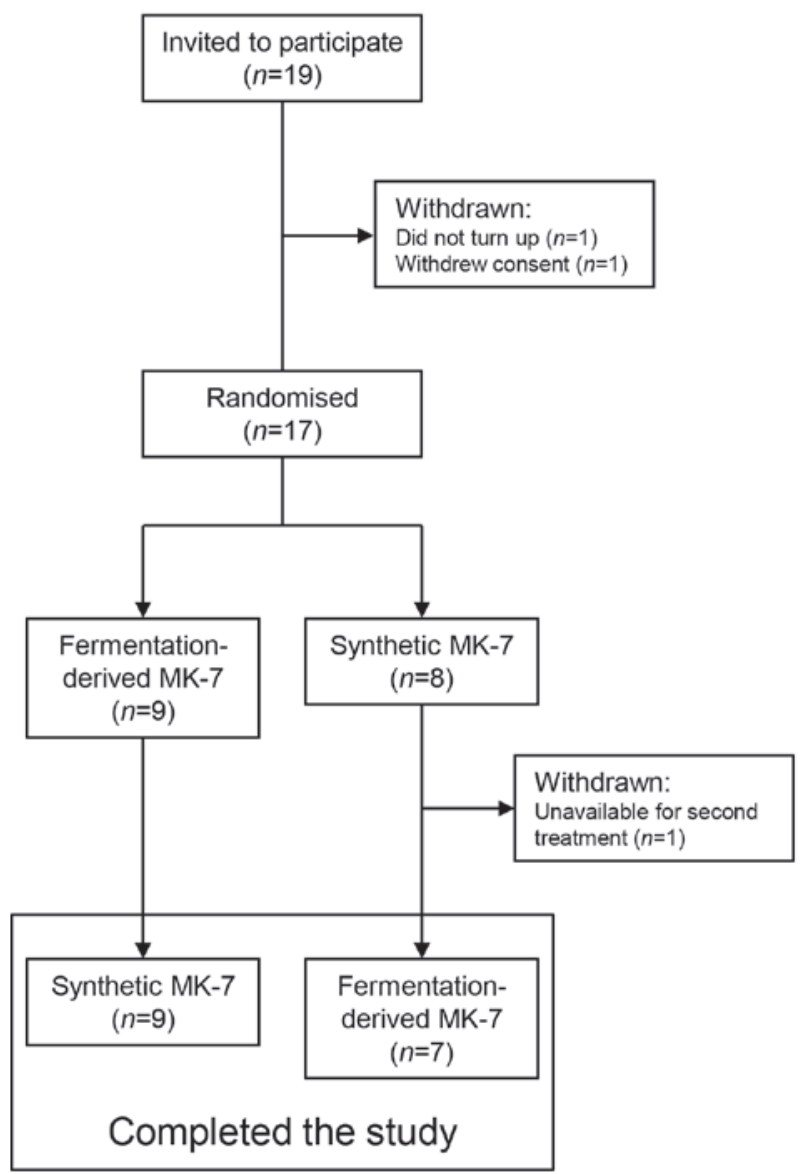

Figure 3: Flow chart for participants in the bioavailability study.

reported by the participants or observed by the investigator. The adverse events were classified according to MedDRA System Organ Classes (SOCs) and Preferred Terms and assessed for their relationship with the study supplement (not related, possibly related, probably related or unknown relationship to the study supplement).

\section{Bioavailability study}

Blood samples $(\sim 5 \mathrm{~mL})$ were obtained during the screening visit and on days 4,22 , and 25 . Serum levels of CRP, creatinine, ALAT and total cholesterol were analysed by Fürst AS as safety variables. The analyses were performed according to standardised, validated protocols. Briefly, CRP was measured by latex-enhanced turbidimetric immunoassay; creatinine was measured by a modified Jaffe method using picric acid; ALAT was measured using a UV test according to an IFCC (International Federation of Clinical
Chemistry and Laboratory Medicine) method; and total cholesterol was measured by a widely used threestep enzymatic method.

\section{Functional study}

Blood samples $(\sim 5 \mathrm{~mL})$ were obtained during the screening visit and on days 22 and 43(+2) for analysis of serum levels of CRP, creatinine, ALAT and total cholesterol by Fürst AS as described above for the bioavailability study.

\section{Statistics}

The data program PK Solutions 2.0TM was used to calculate pharmacokinetic parameters $\left(\mathrm{AUC}, \mathrm{C}_{\max }\right.$, $\mathrm{T}_{\max }$ and $\mathrm{t}_{1 / 2}$ ). Inter-subject coefficient of variation (CV) (\%) was calculated as the standard deviation divided by the mean $(\times 100)$. All statistical analyses were performed using $\mathrm{SAS}^{\circledR}$ version 9.2. The analyses were not stratified by sex. Laboratory data are shown as means and standard errors of the means (SEM). Age is shown as the mean and range. A p-value of $<0.05$ was considered statistically significant.

\section{Bioavailability study}

$\mathrm{AUC}_{(0-72 \mathrm{~h})}$ and $\mathrm{AUC}_{(0-48 \mathrm{~h})}$ were calculated using the linear trapezoidal rule. Synthetic MK-7 and fermentation-derived MK-7 would be considered bioequivalent if the $90 \%$ confidence intervals (CIs) for the bioavailability parameters $\mathrm{AUC}_{(0-72 \mathrm{~h})}$ ratio, $\mathrm{AUC}_{(0-48 \mathrm{~h})}$ ratio and $\mathrm{C}_{\max }$ ratio were within the interval 0.80-1.25. Calculation of the $90 \%$ CIs was based on the mean parameter difference after logarithmic transformation. Values for $\mathrm{AUC}_{(0-72 \mathrm{~h})}, \mathrm{AUC}_{(0-48 \mathrm{~h})}$ and $\mathrm{C}_{\max }$ were compared using ANOVA models (SAS procedure GLM) with period, sequence, and subject within sequence in the model. The data were log transformed prior to the analyses.

\section{Functional study}

For levels of MK-7, 25-hydroxyvitamin $\mathrm{D}_{3}, \mathrm{cOC}$ and ucOC, change from baseline to day 43 was compared between supplement groups by Kruskal-Wallis test (SAS procedure NPAR1WAY). For MK-7, AUC $_{(1-43 \text { days })}$ was calculated and the different groups were compared by 


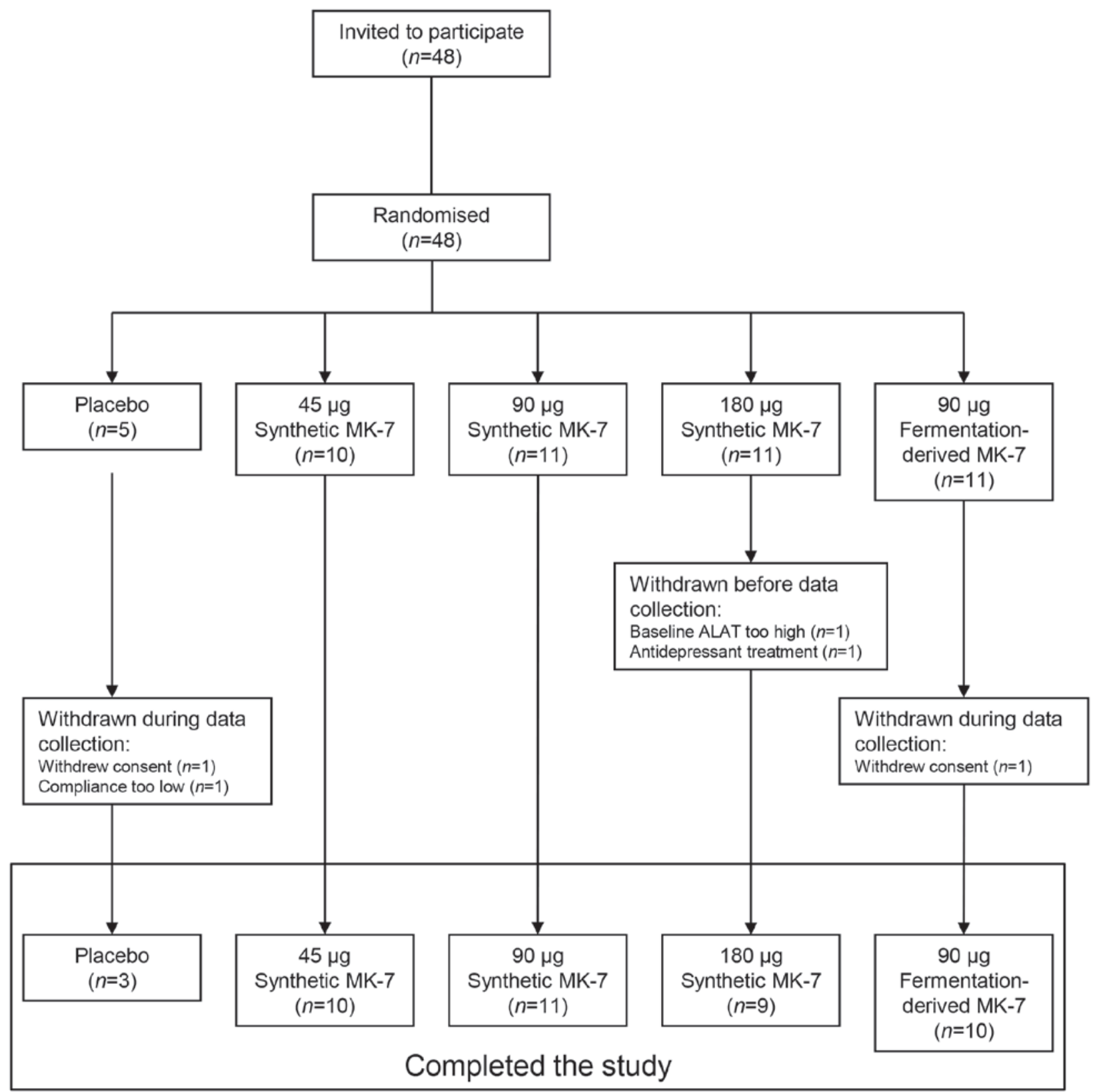

Figure 4: Flow chart for participants in the functional study.

Kruskal-Wallis test. Pairs of supplement groups were compared by Wilcoxon two-sample test. For cOC and ucOC, baseline and day 43 values were compared within groups by Wilcoxon signed rank test.

\section{Safety}

Data from all participants who received at least one dose of any study supplement were included in the safety analysis. For laboratory assessments, change from baseline was analysed by Wilcoxon signed rank test (SAS procedure UNIVARIATE).

\section{Results}

\section{MK-7 product characteristics}

The synthetic form of MK-7 used in the present studies is crystalline all-trans MK-7 of unprecedented purity, 
Table I: Demographic data for supplement groups in the functional study.

\begin{tabular}{lcccccc}
\hline & & & & \multicolumn{2}{c}{ Age (years) } \\
\cline { 5 - 6 } Supplement group & $\mathrm{n}$ & Men & Women & Mean & Range \\
\hline Placebo & 5 & 1 & 4 & 26.8 & $21-41$ \\
$45 \mu \mathrm{g}$ Synthetic MK-7 & 10 & 4 & 6 & 30.2 & $21-60$ \\
$90 \mu \mathrm{g}$ Synthetic MK-7 & 11 & 4 & 7 & 24.6 & $20-45$ \\
$180 \mu \mathrm{g}$ Synthetic MK-7 & 9 & 1 & 8 & 28.6 & $20-41$ \\
$90 \mu \mathrm{g}$ Fermentation-derived MK-7 & 11 & 6 & 5 & 29.4 & $20-52$ \\
\hline
\end{tabular}

as evidenced by HPLC, UV-Vis spectroscopy, NMR, GC/MS and IR spectroscopy analyses; ICP analysis of trace metals; analysis of residual solvents; residue on ignition (ROI) test results; and its well-defined melting point. The synthetic MK-7 contains traces of cis-MK-7. The fermentation-derived MK-7 consists of all-trans MK-7 with traces of all-trans MK-6. HPLC chromatograms (C30 reversed-phase column, detection at $270 \mathrm{~nm}$ ) from both products used in the present studies are shown in figures $2 \mathrm{~A}$ and $\mathrm{B}$. Figure $2 \mathrm{C}$ shows the calculated three-dimensional structure of all-trans MK-7, as modelled by Prof. Svein Samdal and Prof. emer. Lars Skattebøl (University of Oslo).

\section{Subject disposition}

\section{Bioavailability study}

The subject disposition is shown in figure 3. Of the 19 subjects enrolled in the study, 3 withdrew ( 2 before starting the study). No participants withdrew because of adverse events.

\section{Functional study}

48 subjects were enrolled in the study and 5 withdrew: 2 before data collection and 3 during data collection (Figure 4). No participants withdrew because of adverse events. 22 subjects failed to take their capsules on one or more days, including subjects in all supplement groups. Failure to take the capsules may have particularly influenced serum MK-7 levels in the 180 $\mu \mathrm{g}$ synthetic MK-7 group because 5 out of 9 participants failed to take their capsules on several occasions, with compliance ranging from 83 to $100 \%$.

\section{Demographics}

\section{Bioavailability study}

8 subjects received synthetic MK-7 first. Their mean age was 33.6 years (range 20-66) and 7 were women. 9 subjects received fermentation-derived MK-7 first. Their mean age was 28.2 years (range 20-41) and 5 were women.

Table II: Pharmacokinetic values for the bioavailability study.

\begin{tabular}{|c|c|c|c|c|c|}
\hline Treatment & & $\mathrm{AUC}_{(0-72 \mathrm{~h})}(\mathrm{ng}-\mathrm{h} / \mathrm{mL})$ & $\mathrm{AUC}_{(0-48 \mathrm{~h})}(\mathrm{ng}-\mathrm{h} / \mathrm{mL})$ & $\mathrm{C}_{\max }(\mathrm{ng}-\mathrm{h} / \mathrm{mL})$ & $\mathrm{T}_{\max }(\mathrm{h})$ \\
\hline \multirow[t]{5}{*}{ Synthetic MK-7 } & Mean & 95 & 65 & 3.4 & \\
\hline & SEM & 10 & 6 & 0.5 & \\
\hline & Median & & & & 6 \\
\hline & Range & & & & $2-48$ \\
\hline & $\mathrm{CV}(\%)$ & 40 & 37 & 55 & \\
\hline \multirow[t]{5}{*}{ Fermentation-derived MK-7 } & Mean & 104 & 74 & 3.4 & \\
\hline & SEM & 10 & 6 & 0.3 & \\
\hline & Median & & & & 5 \\
\hline & Range & & & & $1-48$ \\
\hline & $\mathrm{CV}(\%)$ & 37 & 33 & 37 & \\
\hline
\end{tabular}

$\mathrm{AUC}=$ Area under the curve; $\mathrm{C}_{\max }=$ maximum serum concentration; $\mathrm{T}_{\max }=$ time at which $\mathrm{Cmax}$ is observed; $\mathrm{CV}=$ inter-subject coefficient of variation. 


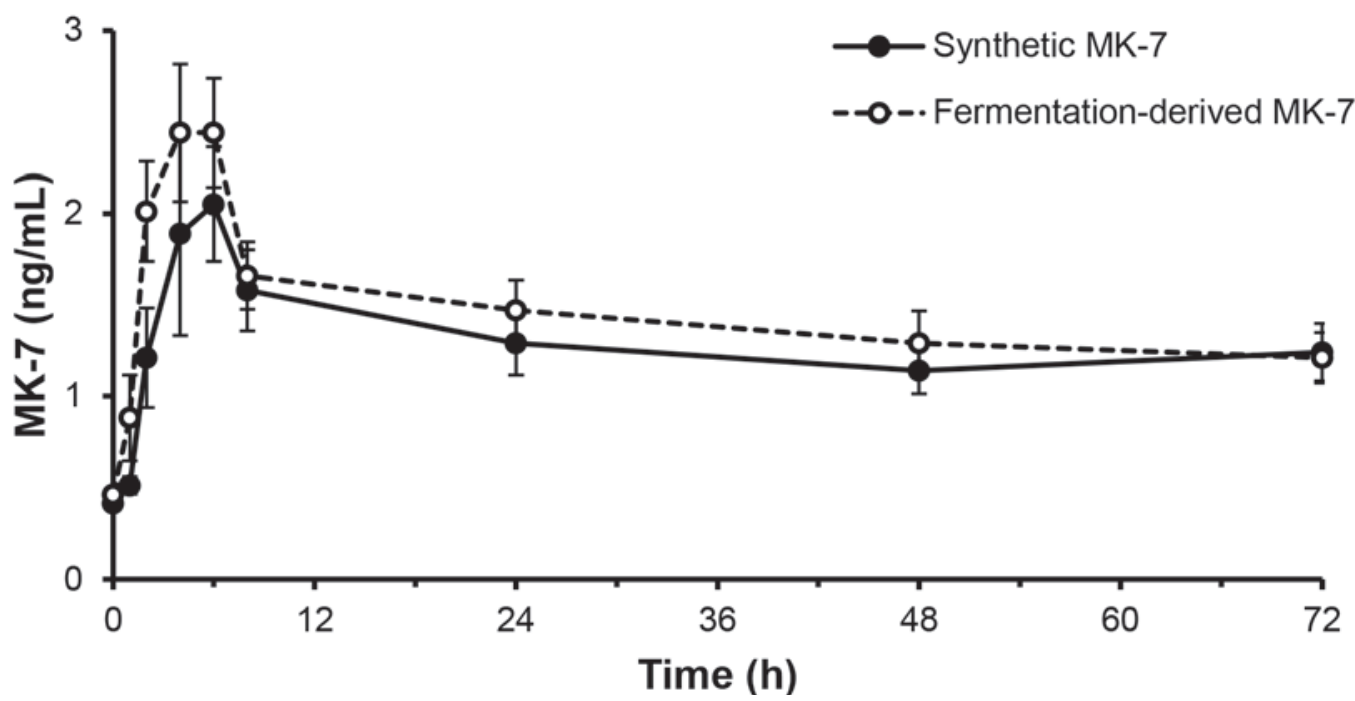

Figure 5: Serum MK-7 concentration vs time for the bioavailability study. Data are shown as means \pm SEM.

\section{Functional study}

Demographic data for the participants are shown in table I. 30 women and 16 men participated.

\section{Bioavailability}

Figure 5 shows the MK-7 concentrations vs time and table II shows key pharmacokinetic values. Median $\mathrm{T}_{\max }$ was $5 \mathrm{~h}$ for fermentation-derived MK-7 and $6 \mathrm{~h}$ for synthetic MK-7. Mean $\mathrm{C}_{\max }$ was 3.4 for both MK-7 supplements. There is considerable inter-subject variation in the values for $\mathrm{T}_{\max }$ (range $\left.1-48 \mathrm{~h}\right), \mathrm{C}_{\max }(0.90-8.58$ $\mathrm{ng} / \mathrm{mL}), \mathrm{AUC}_{(0-48 \mathrm{~h})}(18-114 \mathrm{ng}-\mathrm{h} / \mathrm{mL})$ and $\mathrm{AUC}_{(0-72 \mathrm{~h})}$ (27-185 ng-h/mL).

To assess the degree of bioequivalence of synthetic MK-7 and fermentation-derived MK-7, we calculated ratios of the geometric means for AUC and $\mathrm{C}_{\max }$ values for synthetic MK-7 vs fermentation-derived MK-7. For $\mathrm{AUC}_{(0-48 \mathrm{~h})}$ the ratio was $86 \%$ and the $90 \% \mathrm{CI}$ was $75-99$. For $\mathrm{AUC}_{(0-72 \mathrm{~h})}$ the ratio was $88 \%$ and the $90 \%$ CI was $76-102$. The ratio for $\mathrm{C}_{\max }$ was $96 \%$ and the $90 \%$ CI was 76-120.

After conducting the study, we quantified the exact amount of MK-7 in the provided capsules and discovered that the amount of MK-7 was $9 \%$ higher in the fermentation-derived MK-7 capsules than in the synthetic MK-7 capsules (43.61 vs $39.95 \mu \mathrm{g}$ ). Assuming a linear increase in MK-7 uptake with increasing MK-7 dose [9], we recalculated the geometric mean ratios and $90 \% \mathrm{CIs}$ for $\mathrm{AUC}_{(0-48 \mathrm{~h})}, \mathrm{AUC}_{(0-72 \mathrm{~h})}$ and $\mathrm{C}_{\max }$ with an adjustment factor of 1.09 for the synthetic MK-7 data. The ratio for $\mathrm{AUC}_{(0-48 \mathrm{~h})}$ was $94 \%$ and the $90 \% \mathrm{CI}$ was $81-108$. For $\mathrm{AUC}_{(0-72 \mathrm{~h})}$ the ratio was $96 \%$ and the $90 \%$ CI was $83-111$. For $C_{\max }$ the ratio was $104 \%$ and the $90 \% \mathrm{CI}$ was $83-131$. The recalculated $90 \%$ CIs for $\mathrm{AUC}_{(0-48 \mathrm{~h})}$ and $\mathrm{AUC}_{(0-72 \mathrm{~h})}$ indicate bioequivalence.

Because the serum concentration of MK-7 did not return to the pre-administration level within the 72-h observation period, it was not possible to estimate $t_{1 / 2}$.

\section{Functional aspects}

Synthetic MK-7 showed a non-linear dose-response effect (Figure $6 \mathrm{~A})$. AUC $\mathrm{U}_{(1-43 \text { days })}$ was $17.3( \pm 3.5) \mathrm{ng}$-h/ $\mathrm{mL}$ for the placebo group, $64.1( \pm 20.3) \mathrm{ng}-\mathrm{h} / \mathrm{mL}$ for the $45 \mu \mathrm{g}$ synthetic MK-7 group, $125.6( \pm 48.6) \mathrm{ng}-\mathrm{h} / \mathrm{mL}$ for the $90 \mu \mathrm{g}$ synthetic MK-7 group and $159.6( \pm 28.6)$ $\mathrm{ng}-\mathrm{h} / \mathrm{mL}$ for the $180 \mu \mathrm{g}$ synthetic MK-7 group. The differences versus placebo were all statistically significant ( $\mathrm{p}=0.035$ for $45 \mu \mathrm{g}, \mathrm{p}=0.027$ for $90 \mu \mathrm{g}$ and $\mathrm{p}=0.035$ for $180 \mu \mathrm{g}$; Wilcoxon two-sample test). $\mathrm{AUC}_{(1-43 \text { days })}$ was $111.8( \pm 36.9) \mathrm{ng} \mathrm{h} / \mathrm{mL}$ for the $90 \mu \mathrm{g}$ fermentationderived MK-7 group. The difference versus placebo was statistically significant ( $p=0.031$; Wilcoxon twosample test). The difference in $\mathrm{AUC}_{(1-43 \text { days })}$ between the $90 \mu \mathrm{g}$ synthetic MK-7 group and the $90 \mu \mathrm{g}$ fermentation-derived MK-7 group was not statistically significant ( $p=0.703$; Wilcoxon two-sample test). For both the $90 \mu \mathrm{g}$ synthetic MK-7 group and the $90 \mu \mathrm{g}$ fermentation-derived MK-7 group, the steady-state serum concentration of MK-7 was approximately $2.5 \mathrm{ng} / \mathrm{mL}$ ( $\sim 0.03 \mathrm{ng} / \mathrm{mL} / \mu \mathrm{g}$ MK-7 consumed). The serum concentration of MK-7 in the $180 \mu \mathrm{g}$ synthetic 
A

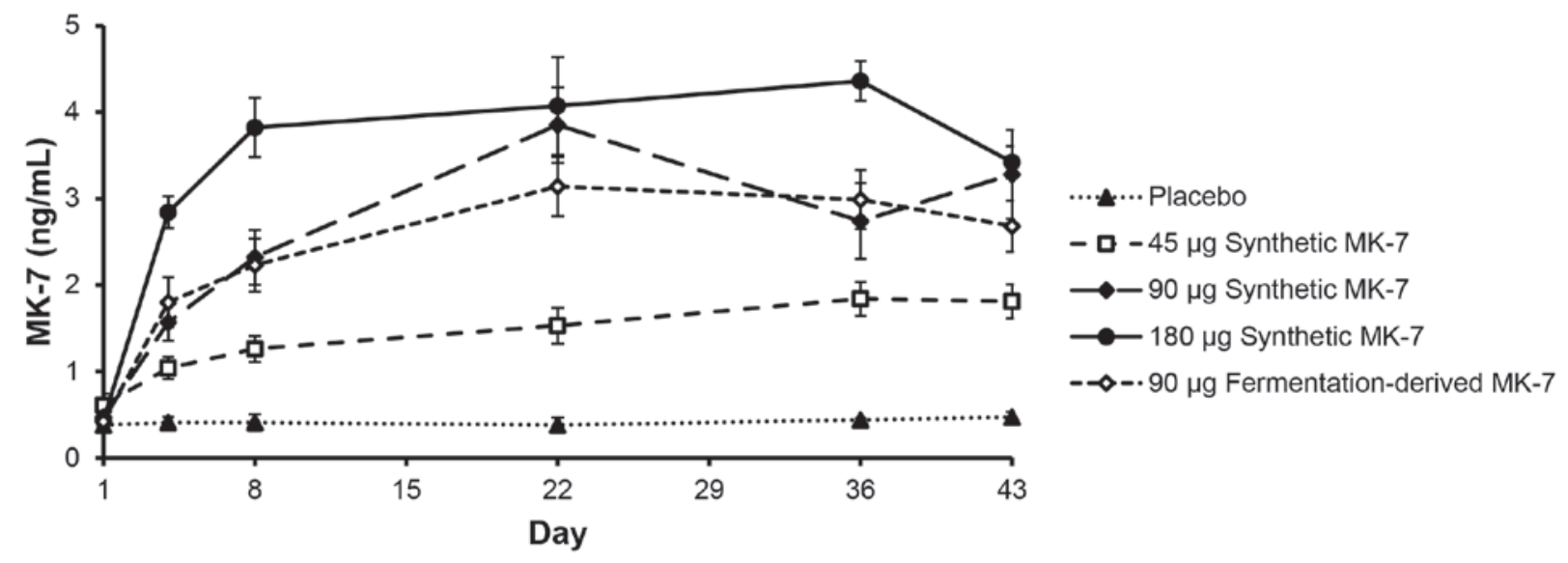

B

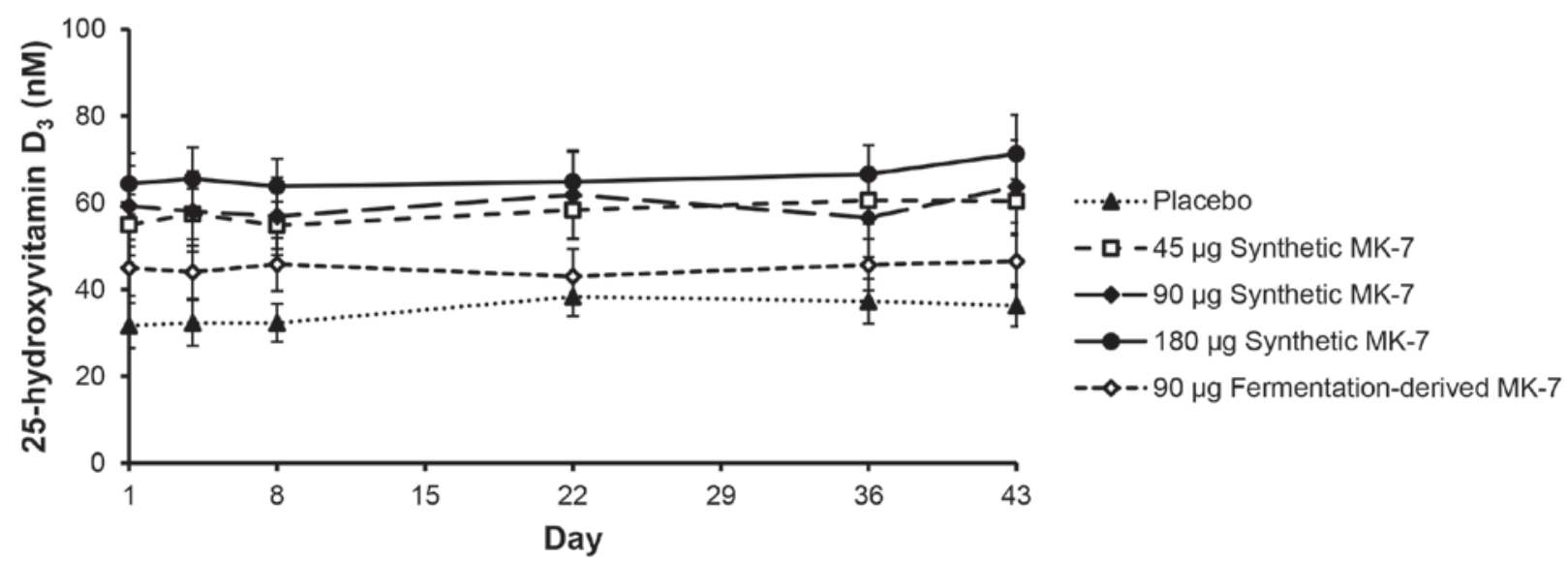

Figure 6: Serum MK-7 concentration vs time and serum 25-hydroxyvitamin $\mathrm{D}_{3}$ concentration vs time for the functional study. A) MK-7. B) 25-hydroxyvitamin $\mathrm{D}_{3}$. Data are shown as means $\pm \mathrm{SEM}$.

MK-7 group decreased somewhat from day 36 to 43, probably due to reduced compliance towards the end of the supplementation period.

There was no significant change in 25-hydroxyvitamin $\mathrm{D}_{3}$ level between baseline and day 43 for any of the supplement groups ( $\mathrm{p}=0.8691$; Kruskal-Wallis test; Figure 6B).

Because degree of carboxylation of $\mathrm{OC}$ is a sensitive marker of human vitamin $\mathrm{K}$ status [8, 9], we analysed levels of cOC (Figure 7 A) and ucOC (Figure 7B) during supplementation. In the $180 \mu \mathrm{g}$ synthetic MK-7 group, mean cOC level showed a statistically significant increase from baseline to day 43 of $29 \%(p=0.021$; Wilcoxon signed rank test). The other groups showed similar trends, although the increases from baseline to day 43 were not statistically significant.

In all groups there was a reduction in mean serum concentration of ucOC with time. For the $90 \mu \mathrm{g}$ and
$180 \mu \mathrm{g}$ synthetic MK-7 groups the ucOC level decreased by $21 \%(\mathrm{p}=0.021$; Wilcoxon signed rank test $)$ and $29 \%$ $(\mathrm{p}=0.013)$, respectively, compared to baseline. The reduction in ucOC level from baseline to day 43 in the $90 \mu \mathrm{g}$ fermentation-derived MK-7 group was not statistically significant. There were no significant differences between the $90 \mu \mathrm{g}$ fermentation-derived MK-7 and $90 \mu \mathrm{g}$ synthetic MK-7 groups in terms of changes in $\mathrm{cOC}$ and ucOC levels from baseline to day 43 .

\section{Safety}

\section{Bioavailability study}

There were no significant changes in serum concentrations of CRP, creatinine, ALAT or total cholesterol after administration of a single dose of fermentation- 
A

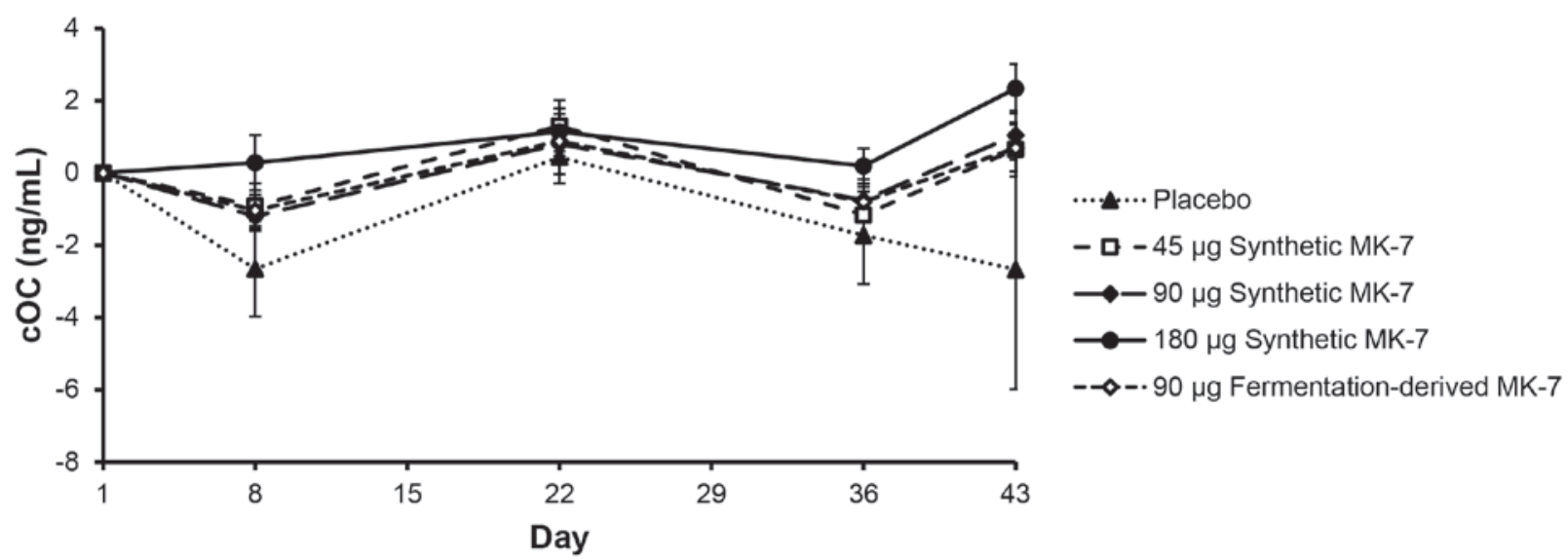

B

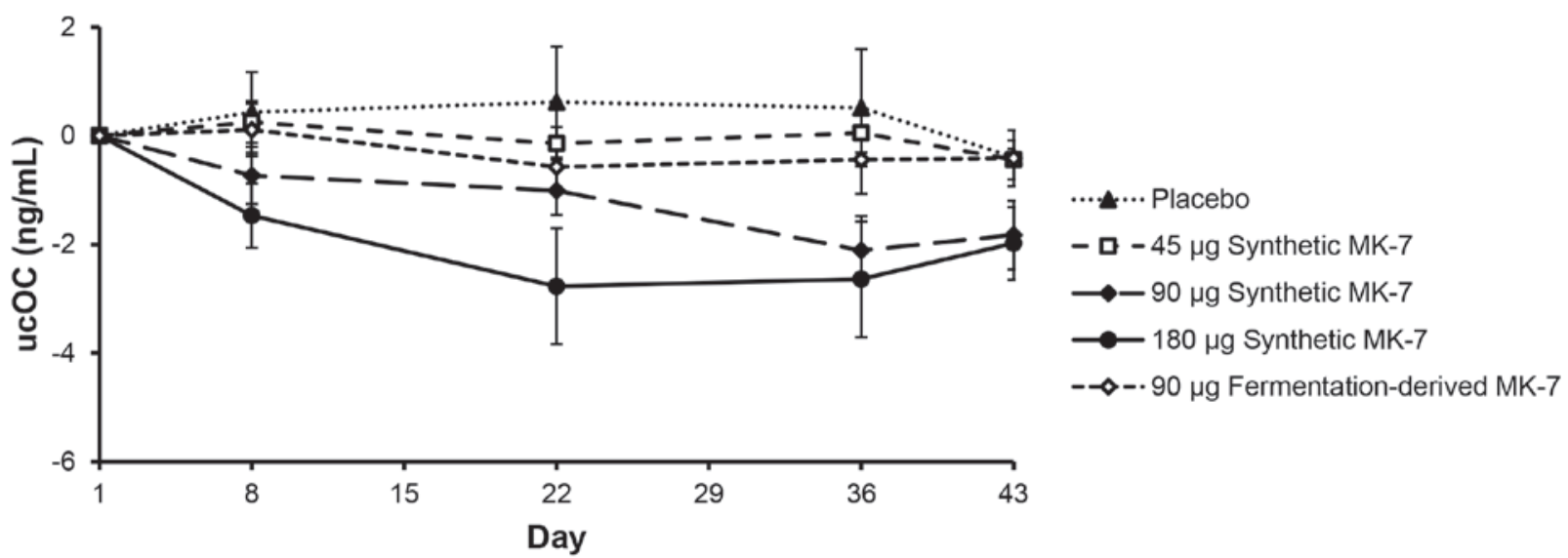

Figure 7: Time-course for serum OC concentrations in the functional study. A) cOC. (B) ucOC. Data are shown as means \pm SEM. Abbreviations: cOC, carboxylated osteocalcin; ucOC, undercarboxylated osteocalcin.

derived MK-7 or synthetic MK-7 (day 4 vs screening and day 25 vs day 22). 6 subjects reported a total of 7 adverse events ( 1 case of rhinitis, 5 cases of nasopharyngitis and 1 case of menstrual pain). All the adverse events were judged unlikely to be related to the study supplement.

\section{Functional study}

Mean serum creatinine concentrations increased by 9.9 $\mu \mathrm{mol} / \mathrm{L}$ from baseline to day 43 in the fermentation-derived MK-7 group ( $p=0.002$; Wilcoxon signed rank test). For serum total cholesterol, a $0.39 \mathrm{mmol} / \mathrm{L}$ reduction in mean level (from baseline to day 43) was registered in the $45 \mu \mathrm{g}$ synthetic MK-7 group ( $\mathrm{p}=0.04$; Wilcoxon signed rank test). These changes were not considered to be clinically relevant. There were no significant changes in CRP or ALAT concentrations in any of the groups.
27 subjects reported a total of 40 adverse events; 32 of these were judged unlikely to be related to the study supplement. The remaining 8 adverse events are shown in table III. In two cases, the adverse events were judged possibly to be related to the study supplement: dry mouth from day 4 to the end of the study (180 $\mu \mathrm{g}$ synthetic MK-7 group) and diarrhoea (fermentation-derived MK-7 group). Another case of diarrhoea in the fermentation-derived MK-7 group was judged probably to be due to the study supplement.

\section{Discussion}

In the present studies we compared the properties of synthetic MK-7 and fermentation-derived MK-7 under controlled clinical conditions. The tested synthetic 
Table III: Individual adverse events in the functional study that were possibly or probably related to the study supplement, or had an unknown relationship to the study supplement.

\begin{tabular}{llll}
\hline Supplement group & System organ class & Preferred term & Relationship to supplement \\
\hline $45 \mu \mathrm{g}$ Synthetic MK-7 & Cardiac disorders & Palpitations & Unknown \\
$45 \mu \mathrm{g}$ Synthetic MK-7 & Gastrointestinal disorders & Abdominal pain & Unknown \\
$45 \mu \mathrm{g}$ Synthetic MK-7 & Gastrointestinal disorders & Diarrhoea & Unknown \\
$45 \mu \mathrm{g}$ Synthetic MK-7 & $\begin{array}{l}\text { Respiratory, thoracic and } \\
\text { mediastinal disorders }\end{array}$ & Epistaxis & Unknown \\
$90 \mu \mathrm{g}$ Synthetic MK-7 & Nervous system disorders & Dizziness & Unknown \\
$180 \mu \mathrm{g}$ Synthetic MK-7 & Gastrointestinal disorders & Dry mouth & Possible \\
$90 \mu \mathrm{g}$ Fermentation-derived MK-7 & Gastrointestinal disorders & Diarrhoea & Possible \\
$90 \mu \mathrm{g}$ Fermentation-derived MK-7 & Gastrointestinal disorders & Diarrhoea & Probable \\
\hline
\end{tabular}

MK-7 contains all-trans MK-7 of very high purity, whereas the fermentation-derived MK-7 contains traces of MK-6. The tested synthetic and fermentationderived MK-7 formulations show bioequivalence, as demonstrated by similar bioavailability; no interaction with another fat-soluble vitamin, 25-hydroxyvitamin $\mathrm{D}_{3}$; and similar effects on OC carboxylation.

In the bioavailability study we found strong evidence for the bioequivalence of synthetic MK-7 and fermentation-derived MK-7 from J-Oil Mills, with $90 \%$ CIs for $\mathrm{AUC}_{(0-48 \mathrm{~h})}$ ratio and $\mathrm{AUC}_{(0-72 \mathrm{~h})}$ ratio within the $0.80-1.25$ interval specified by the European Medicines Agency [27]. The $90 \% \mathrm{CI}$ for $\mathrm{C}_{\max }$ ratio (83-131) was marginally outside this interval, but the interval for $\mathrm{C}_{\max }$ ratio can be widened if intra-subject variability is high $(>30 \%)$. A recent study provided tentative evidence for high intra-subject variation in MK-7 uptake [28].

We also observed an increase in serum cOC concentration and a reduction in serum ucOC concentration after daily intake of the highest dose of synthetic MK-7 $(180 \mu \mathrm{g})$ for 6 weeks. The fermentation-derived MK-7 group showed similar trends. This shows that synthetic MK-7 supplementation induces OC carboxylation, as expected. The steady-state serum concentration of MK-7 increased over time for all three doses and levelled off after 8 days (Figure 6A). There was no linear dose-response for steady-state concentration. A linear dose-response has been observed by others [9]. Synthetic and fermentation-derived MK-7 gave similar steady-state concentrations for intake of 90 $\mu \mathrm{g} /$ day, demonstrating that the products have similar bioavailability during long-term use.

Only a few studies have investigated the bioavailability and single-dose kinetics of MK-7 [9, 15, 29, 30]. In a recent study, Knapen and colleagues compared the bioavailability of MK-7 in four clinical trials us- ing different formulations of capsules and tablets [28]. They found no difference in uptake between tablets and capsules or between different carriers for MK-7. $\mathrm{T}_{\max }$ was $6 \mathrm{~h}$ for tablets and 2-4 h for capsules [28]. In our study $\mathrm{T}_{\max }$ varied between 1 and $48 \mathrm{~h}$ for fermentationderived MK-7, and between 2 and $48 \mathrm{~h}$ for synthetic MK-7. Knapen and colleagues similarly reported intersubject differences for $\mathrm{T}_{\max }$ after oral MK-7 intake [28].

Only one previous study has provided data for long-term intake of an MK-7 supplement and steadystate concentrations of MK-7 in serum [9]. After intake of $0.22 \mu$ moles $(141 \mu \mathrm{g})$ of MK-7 per day for 40 days, the serum concentration was $6 \mathrm{ng} / \mathrm{mL}$, equivalent to $0.04 \mathrm{ng} / \mathrm{mL} / \mu \mathrm{g}$ MK-7 consumed. In our study the steady-state concentration was somewhat lower: $\sim 0.03 \mathrm{ng} / \mathrm{mL} / \mu \mathrm{g}$ MK-7 for intake of $90 \mu \mathrm{g}$ of MK-7 per day. The results are not directly comparable as our study differs from the previous study with respect to study population, product formulation and analytical techniques.

Studies have shown that uptake of vitamin K from the intestine depends on many factors such as bile salts, $\mathrm{pH}$, food matrix (i.e. fat content), genetics, and age [31-33]. The uptake of vitamin $\mathrm{K}_{1}$ from capsules was previously observed to be dependent on the food matrix [34]. However, recent studies suggest that for bioavailability of MK-7 as a nutritional supplement, the carrier material may not play an important role [15]. Sunflower oil was chosen as the carrier in the present studies because it is an edible oil often used as a carrier in pharmacological studies.

There was a predominance of female subjects in both the bioavailability and functional studies. Whether there is a sex difference in MK-7 uptake is unclear. However, in agreement with a previous study [28] we found considerable inter-subject differences in MK-7 uptake in healthy adult subjects. 
ucOC is a sensitive functional marker for vitamin $\mathrm{K}$ status [8]. Elevated concentrations of ucOC are associated with vitamin $\mathrm{K}$ deficiency and an increased risk of hip fractures $[5,13,14,35,36]$. Supplementation with vitamin $\mathrm{K}_{2}$ promotes a decrease in ucOC, suggesting that vitamin $\mathrm{K}_{2}$ contributes to OC carboxylation $[9,37]$. In the functional study, we observed that synthetic and fermentation-derived MK-7 gave similar steady-state serum concentrations of MK-7, and had similar abilities to reduce the serum ucOC concentration, although the reduction from baseline in the fermentation-derived MK-7 group was not statistically significant.

The data for $\mathrm{COC}$ show considerable variation over time (Figure 7 A). For example, there were unexpected reductions in serum cOC levels in all groups between day 22 and day 36 . Data concerning compliance (based on the CRFs) suggest that several participants occasionally failed to take their capsules during this period, which may have influenced the results.

Three adverse events in the functional study were judged to be possibly or probably related to the study material: dry mouth in 1 subject on $180 \mu \mathrm{g}$ synthetic MK-7 and diarrhoea in 2 subjects during daily intake of $90 \mu \mathrm{g}$ of fermentation-derived MK-7. Vitamin $\mathrm{K}_{2}$ is generally considered safe [38]. In a previous study, no side effects related to MK-7 were reported after daily intake of $180 \mu \mathrm{g}$ for 3 years [15]. We previously conducted a 90-day toxicology study in rats [24]. The no observed adverse effect level (NOAEL) of synthetic MK-7, when administered orally to rats for 90 days, was $10 \mathrm{mg} / \mathrm{kg} / \mathrm{day}$, the highest dose tested.

\section{Limitations and strengths}

One limitation of the functional study is the small placebo group. We allocated fewer subjects to the placebo group because we chose to focus our resources on observing a treatment effect, because we were primarily interested in the time and concentration effects of MK-7 supplementation. Unfortunately, 2 of the 5 subjects who withdrew from the study were in the placebo group, reducing the likelihood of finding significant differences compared to the active supplement groups. Another limitation is the large inter-subject variation in some of the data. In order to mitigate this problem in the bioavailability study we offered all participants a standardised breakfast containing $\sim 25 \mathrm{~g}$ of fat. This may be important because $\mathrm{K}$ vitamins are lipophilic and their bioavailability may be increased by dietary fat [9], although this is somewhat controversial [15]. A further limitation is that the synthetic MK-7 capsules contained less MK-7 than the fermentationderived MK-7 capsules. This meant that we had to recalculate the AUC and $\mathrm{C}_{\max }$ ratios and $90 \%$ CIs using an adjustment factor, assuming a linear increase in MK-7 uptake with increasing dose. There is evidence to support a linear association between MK-7 dose and MK-7 uptake for the MK-7 dose range used in the present studies [9]. An important strength of our studies is the use of fermentation-derived MK-7 produced by J-Oil Mills as the active ingredient in the control product, because this was used in recently published clinical studies on the effects of MK-7 [9, 15, 39, 40]. This strengthens our ability to compare our present findings with published findings on MK-7.

\section{Conclusions}

We have demonstrated that the tested synthetic MK-7 is bioequivalent to fermentation-derived MK-7 with respect to absorption, giving similar peak levels and AUC values after single-dose administration. Furthermore, synthetic MK-7 has a similar ability to increase OC carboxylation as fermentation-derived MK-7. Our data suggest that there is no difference in biological activity between the tested synthetic MK-7 and fermentation-derived MK-7.

\section{Acknowledgements}

We thank medical writer Stephen Gilliver of TFS $\mathrm{AB}$ for helping us to draft this manuscript, Ane C. Westerberg for contributing to the intervention and evaluating the manuscript, and the contract laboratory Vitas AS for carrying out the analyses of MK-7, ucOC and OC.

The study was financed by Kappa Bioscience AS, Oslo, Norway. Kappa Bioscience AS is the owner of the brand K2VITAL ${ }^{\circledR}$.

Mona Møller, Christian A. Drevon (Principle Investigator), and Ingebjørg Baksaas designed the study and contributed to the data analyses. Ingrid M. Fange Gjelstad and Christian A. Drevon were responsible for carrying out the study. Tone Grande was responsible for statistics and data analysis. Inger Reidun Aukrust was responsible for production and characterisation of K2VITAL ${ }^{\circledR}$. Ingebjørg Baksaas was responsible for monitoring of the study. All authors evaluated the manuscript critically and approved the final version. 


\section{Conflict of Interest}

Mona Møller is a shareholder of and consultant for Kappa Bioscience AS.

Inger Reidun Aukrust is a shareholder and board member of Kappa Bioscience AS.

Christian A. Drevon is a founder, shareholder and board member of DBG AS (www.dbg.no) and Vitas AS (www.vitas.no), which conducted the clinical studies and analysed serum samples, respectively. Ingebjørg Baksaas was previously the CEO and a shareholder of Mericon AS.

The other authors declare no conflicts of interest.

\section{References}

1. Booth, S.L. and Suttie, J.W. (1998) Dietary intake and adequacy of vitamin K. J. Nutr. 128, 785-788.

2. Drevon, C.A., Henriksen, H.B., Sanderud, M., Gundersen, T.E. and Blomhoff, R. (2004) [Biological effects of vitamin $\mathrm{K}$ and concentration of vitamin $\mathrm{K}$ in Norwegian food]. Tidsskr. Nor. Laegeforen 124, $1650-1654$.

3. Shearer, M.J. and Newman, P. (2008) Metabolism and cell biology of vitamin K. Thromb. Haemost. 100, $530-547$.

4. Vermeer, C. (2012) Vitamin K: the effect on health beyond coagulation - an overview. Food Nutr. Res. 56.

5. Booth, S.L. (2009) Roles for vitamin K beyond coagulation. Annu. Rev. Nutr. 29, 89-110.

6. Boskey, A.L., Gadaleta, S., Gundberg, C., Doty, S.B., Ducy, P. and Karsenty, G. (1998) Fourier transform infrared microspectroscopic analysis of bones of osteocalcin-deficient mice provides insight into the function of osteocalcin. Bone 23, 187-196.

7. Luo, G., Ducy, P., McKee, M.D., Pinero, G.J., Loyer, E., Behringer, R.R. and Karsenty, G. (1997) Spontaneous calcification of arteries and cartilage in mice lacking matrix GLA protein. Nature 386, $78-81$.

8. Sokoll, L.J., Booth, S.L., O'Brien, M.E., Davidson, K.W., Tsaioun, K.I. and Sadowski, J.A. (1997) Changes in serum osteocalcin, plasma phylloquinone, and urinary gamma-carboxyglutamic acid in response to altered intakes of dietary phylloquinone in human subjects. Am. J. Clin. Nutr. 65, 779-784.

9. Schurgers, L.J., Teunissen, K.J., Hamulyák, K., Knapen, M.H., Vik, H. and Vermeer, C. (2007) Vitamin K-containing dietary supplements: comparison of synthetic vitamin $\mathrm{K} 1$ and natto-derived menaquinone-7. Blood 109, 3279-3283.

10. Schurgers, L.J., Shearer, M.J., Hamulyák, K., Stöcklin, E. and Vermeer, C. (2004) Effect of vitamin K intake on the stability of oral anticoagulant treatment: doseresponse relationships in healthy subjects. Blood 104, $2682-2689$

11. Knapen, M.H., Schurgers, L.J. and Vermeer, C. (2007) Vitamin K2 supplementation improves hip bone geometry and bone strength indices in postmenopausal women. Osteoporos. Int. 18, 963-972.

12. Braam, L.A., Knapen, M.H., Geusens, P., Brouns, F. and Vermeer, C. (2003) Factors affecting bone loss in female endurance athletes: a two-year follow-up study. Am. J. Sports Med. 31, 889-895.

13. Szulc, P., Chapuy, M.C., Meunier, P.J. and Delmas, P.D. (1993) Serum undercarboxylated osteocalcin is a marker of the risk of hip fracture in elderly women. J. Clin. Invest. 91, 1769-1774.

14. Szulc, P., Chapuy, M.C., Meunier, P.J. and Delmas, P.D. (1996) Serum undercarboxylated osteocalcin is a marker of the risk of hip fracture: a three year followup study. Bone 18, 487-488.

15. Knapen, M.H., Drummen, N.E., Smit, E., Vermeer, C. and Theuwissen, E. (2013) Three-year low-dose menaquinone-7 supplementation helps decrease bone loss in healthy postmenopausal women. Osteoporos. Int. 24, 2499-2507.

16. Weber, P. (1997) Management of osteoporosis: is there a role for vitamin K? Int. J. Vitam. Nutr. Res. 67, $350-356$.

17. Weber, P. (1999) The role of vitamins in the prevention of osteoporosis - a brief status report. Int. J. Vitam. Nutr. Res. 69, 194-197.

18. Weber, P. (2001) Vitamin K and bone health. Nutrition 17, 880-887.

19. Eisai Co., Ltd. (2014) Vitamin K2 Preparation for Treatment of Osteoporosis. Glakay ${ }^{\circledR}$ Capsules $15 \mathrm{mg}$. Available from: http://www.eisai.jp/medical/products/ di/EPI/GLA_SC_EPI.pdf.

20. Kamao, M., Suhara, Y., Tsugawa, N., Uwano, M., Yamaguchi, N., Uenishi K., Ishida, H., Sasaki, S. and Okano, T. (2007) Vitamin K content of foods and dietary vitamin $\mathrm{K}$ intake in Japanese young women. J. Nutr. Sci. Vitaminol. (Tokyo) 53, 464-470.

21. Ikeda, Y., Iki, M., Morita, A., Kajita, E., Kagamimori, S., Kagawa, Y. and Yoneshima, H. (2006) Intake of fermented soybeans, natto, is associated with reduced bone loss in postmenopausal women: Japanese Population-Based Osteoporosis (JPOS) Study. J. Nutr. 136, 1323-1328. 
22. Cranenburg, E.C., Schurgers, L.J. and Vermeer, C. (2007) Vitamin K: the coagulation vitamin that became omnipotent. Thromb. Haemost. 98, 120-125.

23. Kaneki, M., Hodges, S.J., Hosoi, T., Fujiwara, S., Lyons, A., Crean, S.J., Ishida, N., Nakagawa, M., Takechi, M., Sano, Y., Mizuno, Y., Hoshino, S., Miyao, M., Inoue, S., Horiki, K., Shiraki, M., Ouchi, Y. and Orimo, H. (2001) Japanese fermented soybean food as the major determinant of the large geographic difference in circulating levels of vitamin K2: possible implications for hip-fracture risk. Nutrition 17, 315-321.

24. Pucaj, K., Rasmussen, H., Møller, M. and Preston, T. (2011) Safety and toxicological evaluation of a synthetic vitamin K2, menaquinone-7. Toxicol. Mech. Methods. 21, 520-532.

25. Matschiner, J.T. and Bell, R.G. (1972) Metabolism and vitamin $\mathrm{K}$ activity of cis phylloquinone in rats. $\mathrm{J}$. Nutr. 102, 625-629.

26. Knauer, T.E., Siegfried, C., Willingham, A.K. and Matschiner, J.T. (1975) Metabolism and biological activity of cis- and trans-phylloquinone in the rat. $\mathrm{J}$. Nutr. 105, 1519-1524.

27. CHMP. (2010) Guideline on the Investigation of Bioequivalence. European Medicines Agency. London, UK.

28. Knapen, M.H.J., Vermeer, C., Braam L.A.J.L.M. and Theuwissen, E. (2014) Pharmacokinetics of menaquinone-7 (vitamin K2) in healthy volunteers. J. Clin. Trials 4, 160.

29. Schurgers, L.J. and Vermeer, C. (2002) Differential lipoprotein transport pathways of K-vitamins in healthy subjects. Biochim. Biophys. Acta 1570, 27-32.

30. Sato, T., Schurgers, L.J. and Uenishi, K. (2012) Comparison of menaquinone-4 and menaquinone-7 bioavailability in healthy women. Nutr. J. 11, 93.

31. Gijsbers, B.L., Jie, K.S. and Vermeer, C. (1996) Effect of food composition on vitamin $\mathrm{K}$ absorption in human volunteers. Br. J. Nutr. 76, 223-229.

32. Hollander, D., Rim, E. and Ruble, P.E. (1977) Vitamin K2 colonic and ileal in vivo absorption: bile, fatty acids, and $\mathrm{pH}$ effects on transport. Am. J. Physiol. 233, E124-E129.

33. Vermeer, C., Gijsbers, B.L., Cr ciun, A.M., Groenenvan Dooren, M.M. and Knapen, M.H. (1996) Effects of vitamin $\mathrm{K}$ on bone mass and bone metabolism. J. Nutr. 126, 1187S-1191S.

34. Jones, K.S., Bluck, L.J., Wang, L.Y., Stephen, A.M., Prynne, C.J. and Coward, W.A. (2009) The effect of different meals on the absorption of stable isotope-labelled phylloquinone. Br. J. Nutr. 102, 1195-1202.

35. Booth, S.L., Dallal, G., Shea, M.K., Gundberg, C., Peterson, J.W. and Dawson-Hughes, B. (2008) Effect of vitamin $\mathrm{K}$ supplementation on bone loss in elderly men and women. J. Clin. Endocrinol. Metab. 93, $1217-1223$.

36. Luukinen, H., Käkönen, S.M., Pettersson, K., Koski, K., Laippala, P., Lövgren, T., Kivelä, S.L. and Väänänen, H.K. (2000) Strong prediction of fractures among older adults by the ratio of carboxylated to total serum osteocalcin. J. Bone Miner. Res. 15, $2473-2478$.

37. Theuwissen, E, Cranenburg, E.C., Knapen, M.H., Magdeleyns, E.J., Teunissen, K.J., Schurgers L.J., Smit, E. and Vermeer, C. (2012) Low-dose menaquinone-7 supplementation improved extrahepatic vitamin $\mathrm{K}$ status, but had no effect on thrombin generation in healthy subjects. Br. J. Nutr. 108, $1652-1657$.

38. EFSA. (2008) Scientific Opinion of the Panel on Dietetic Products Nutrition and Allergies on a request from the European Commission on the safety of 'Vitamin K2'. EFSA J. 822, 1-32.

39. Knapen, M.H., Braam, L.A., Drummen, N.E., Bekers, O., Hoeks, A.P. and Vermeer, C. (2015) Menaquinone-7 supplementation improves arterial stiffness in healthy postmenopausal women: double-blind randomised clinical trial. Thromb. Haemost. 113, 1135-1144.

40. J-Oil Mills. Fermentation-derived MK-7 produced by J-Oil Mills was used in the studies in references 15 and 39. Personal communication, 25 June 2015.

Mona Møller

Kappa Bioscience AS

Gaustadalléen 21

0349 Oslo

Norway

Tel: +4791333175

mona.moller@kappabio.com 